\title{
An improved differential evolution algorithm-based optimal series compensation voltage control strategy for an active distribution network
}

DOI:

10.1002/etep.2386

\section{Document Version}

Accepted author manuscript

Link to publication record in Manchester Research Explorer

Citation for published version (APA):

Zhang, Z., Crossley, P., Xu, B., \& Ma, J. (2017). An improved differential evolution algorithm-based optimal series compensation voltage control strategy for an active distribution network. International Transactions on Electrical Energy Systems. https://doi.org/10.1002/etep.2386

\section{Published in:}

International Transactions on Electrical Energy Systems

\section{Citing this paper}

Please note that where the full-text provided on Manchester Research Explorer is the Author Accepted Manuscript or Proof version this may differ from the final Published version. If citing, it is advised that you check and use the publisher's definitive version.

\section{General rights}

Copyright and moral rights for the publications made accessible in the Research Explorer are retained by the authors and/or other copyright owners and it is a condition of accessing publications that users recognise and abide by the legal requirements associated with these rights.

\section{Takedown policy}

If you believe that this document breaches copyright please refer to the University of Manchester's Takedown Procedures [http://man.ac.uk/04Y6Bo] or contact uml.scholarlycommunications@manchester.ac.uk providing relevant details, so we can investigate your claim.

\section{OPEN ACCESS}




\title{
An Improved Differential-Evolution-Algorithm-Based Optimal Series Compensation Voltage Control Strategy for an Active Distribution Network
}

\author{
Zhihua ZHANG ${ }^{1}$, Peter CROSSLEY ${ }^{2}$, Bingyin $\mathrm{XU}^{3}$ and Jun $\mathrm{MA}^{4}$
}

\begin{abstract}
${ }^{1}$ Information and Control Engineering College, China University of Petroleum, Qingdao, CO 266580, China.

${ }^{2}$ School of Electrical \& Electronic Engineering, the University of Manchester, Manchester, CO M139PL, UK.

${ }^{3}$ College of Electrical and Electronic Engineering, Shandong University of Technology, Zibo, CO 255049, China.

${ }^{4}$ State Grid Shandong Binzhou Power Supply Company, Binzhou, CO 256600, China.
\end{abstract}

\section{Correspondence}

Zhihua Zhang, No.66

Changjiang West Road,

Huangdao District, Qingdao,

China. 266580

Email: zzh-upc@163.com

\begin{abstract}
SUMMARY
A distribution network with distributed generation (DG) is usually called an active distribution network. The voltage quality in an active distribution network tends to degrade because of the bidirectional power flow in the network and the random output characteristic of DG. Existing voltage control methods cannot effectively address this issue. In this article, an improved differential evolution (DE)-algorithm-based optimal series compensation voltage control method for an active distribution network is presented. It is assumed that the series compensating voltage is produced flexibly by modern power electronics equipment. The quantitative relationship connecting the node voltage deviation, network power loss and compensating voltage is analysed. The optimal control model, including the power loss and load node voltage, is constructed. Then, an improved DE algorithm is proposed to solve the optimal model, which combines the standard DE approach with the simulated annealing and adaptive mutation operator method. The optimal control model can be solved effectively by the improved algorithm. A simulation model is developed based on the IEEE 33 standard distribution network with DG. Simulation results confirm the validity of the optimal control model and the advantages of the improved DE algorithm.
\end{abstract}

\section{KEYWORDS}

active distribution network, series compensation, optimal voltage control, improved differential evolution algorithm.

\section{Introduction}

Voltage quality is an important parameter to describe a power system [1][2]. Distributed generation (DG) has been developing rapidly because of the energy crisis and environmental problems. DG is commonly injected into the distribution network, which is usually described as an active distribution network [3][4]. DG and loads work with both random and intermittent characteristics; the power flow in an active distribution network is bidirectional. The voltage quality tends to be worse than that of a radial network [5]-[7]. There are certain voltage regulation measurements, such as the on-load tap changer and shunt capacitor, that can regulate the stable voltage for the conventional distribution network, but they cannot meet the voltage control demands of an active distribution network, particularly in adjustments of speed and continuity [8]-[15]. This limitation is the primary factor governing the amount of DG that can be injected into the distribution system.

Series capacitor compensation technology has been widely used in transmission systems to regulate system parameters to enhance transmission capability and operational stability [16]. In a distribution network, the equivalent resistance is usually greater than the equivalent reactance; in some cases, their ratio is over 5 . The series capacitor can compensate for the voltage drop across the equivalent resistance along the distribution line, but it cannot 
accommodate the voltage drop of the equivalent resistance [17]. In contrast, a series capacitor can automatically change the compensating voltage according to the current flowing through it. When amounts of DG are injected by the feeder or customer side, the power flow in the distribution network will be bidirectional. In this case, the voltage will degrade under the control of the series capacitor. An interline dynamic voltage restorer method is presented, and the compensation range is analysed for different voltage sag types [18]. The unified power flow controller (UPFC) as a flexible alternative current transmission system (FACTS) apparatus has a powerful capability to adjust the power flow [19]. This method has been used successfully in transmission systems to enhance transmission capability; it can control the compensation voltage amplitude and phase continuously and rapidly. A UPFC-based optimal power flow control model for a closed-loop distribution network has been presented that incorporates the power loss and node voltage [20]-[22]. In those reports, the UPFC-based optimal control model including load node voltage and power loss was constructed, but the solution algorithm for the optimal control model was not addressed.

The power flow control model is a multi-objective nonlinear optimization problem, which is challenging to solve by conventional algebraic analysis. Artificial intelligence (AI) is well suited to solve such nonlinear optimization problems [23]. In 1995, Rainer Storn and Kenneth Price presented a differential evolution (DE) algorithm [24]. Distinct from other evolutionary algorithms, mutation in DE is completed by the difference of multiple sectors selected at random. This approach can solve complicated nonlinear problems with high efficiency and satisfactory robustness [25][26]. It is challenging for standard DE algorithms to produce appropriate initial populations because the mutation is highly random and because the calculation process is greatly influenced by the algorithm parameters. To obtain an optional initial population for the genetic algorithm, one initial individual is produced randomly that can meet the constraint condition. Then, the remaining individuals are gradually regulated similar to the first individual until the entire population meets the constraint condition [27]. The initial population production process can be effectively optimized by this method, but the distribution breadth is insufficient in the feasible solution region. The method for adaptive mutation operator is presented elsewhere [28][29]. In this method, the zooming coefficient is much larger in the initial period to increase the breadth of the population distribution. The zooming coefficient becomes smaller over subsequent periods to speed up the convergence rate. Simulated annealing strategy is also used to improve the DE algorithm [30]. The variation is adjusted by changing annealing factors to escape the local minimum solution in the beginning stage. The best parent individual will lead the variation to enhance the local searching ability in the late stage. This method can effectively improve the convergence rate. An adaptive DE algorithm has been proposed [31]. Its mutation and crossover operators continue to change during the evolution process, and unsuitable parameters can be avoided to a certain extent. A DE algorithm incorporating the improved method has been used to solve the optimal dispatch problem for hydroelectric power [32]. It can effectively enhance calculation efficiency, but the convergence rate of this algorithm is random because the parameter selection is not deterministically controlled.

This article presents an optimal series compensation voltage control method for an active distribution network and an improved DE algorithm to solve this optimal model. Simulation results based on the IEEE 33 bus distribution network confirm that the optimal voltage control method can improve the voltage quality and lower the active power loss. The improved DE algorithm can solve the optimization problem universally with high efficiency. 


\section{Relationship between the compensation voltage and operating parameters of an active distribution network}

\subsection{Relationship between series compensation voltage and power loss}

A radial distribution feeder with $\mathrm{n}$ load branches and DG is shown in Fig. 1. DG is injected at the feeder end. It is assumed to act as a voltage source. $\dot{I}_{D G}$ is the current injected by DG, $\dot{I}_{i}$ is the current of feeder section i, and $\dot{I}_{L i}$ is the current of load $\mathrm{i}$.

All loads are assumed to behave as constant-current models. $\dot{U}_{i}$ is the voltage of load i. $Z_{i}$ is the equivalent impedance of feeder section $\mathrm{i}$, and $Z_{i}=R_{i}+j \omega L_{i}$.

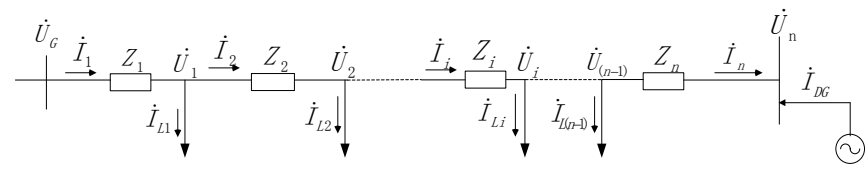

FIGURE 1 Equivalent circuit of one feeder with DG and $n$ load branches

When there is no series compensation, the loop current $\dot{I}_{\text {loop }}$ can be expressed as

$$
\dot{I}_{\text {loop }}=\frac{\Delta \dot{U}-\sum_{i=1}^{n} j \omega L_{i} \dot{I}_{i}}{R_{\Sigma}}
$$

where $\Delta \dot{U}=\dot{U}_{G}-\dot{U}_{n}$ and $R_{\Sigma}=\sum_{i=1}^{n} R_{i}$. When $\Delta \dot{U}$ is equal to $\sum_{i=1}^{n} j \omega L_{i} \dot{I}_{i}$, the circle current $\dot{I}_{\text {loop }}$ is 0. In this case, the power loss is minimal and can be expressed as $P_{\text {loss-min }}$.

The UPFC has powerful power flow control capability, which is used here to produce the series compensation voltage $\dot{U}_{S C}$. As discussed above, when $\Delta \dot{U}+\dot{U}_{S C}=\sum_{i=1}^{3} j \omega L_{i} \dot{I}_{i}$, the power loss is minimal; thus, it is necessary to adjust the compensation voltage further to improve the load voltage. Consequently, the loop current will change, and the power loss will increase. $\Delta \dot{I}_{\text {loop }}^{\prime}$ is the loop current increment based on the condition of minimal power loss, and $P_{\text {loss }}^{\prime}$ is the power loss after further adjustment.

$$
P_{\text {loss }}^{\prime}=P_{\text {loss }-\min }+3 \times \sum_{i=1}^{n} R_{i}\left|\Delta \dot{I}_{\text {loop }}^{\prime}\right|^{2}
$$

The power loss increment is related only to the amplitude of the loop current increment and is unrelated to its phase. The new loop current $\dot{I}_{\text {loop }}^{\prime}$ can be described simply as

$$
\dot{I}_{\text {loop }}^{\prime}=\dot{I}_{\text {loop }}+\frac{\dot{U}_{S C}}{Z_{\Sigma}}
$$

Therefore, the relationship between the series compensation voltage and active power loss for the network in Fig. 1 can be expressed as

$$
P_{\text {loss }}^{\prime}=P_{\text {loss-min }}+3 \times R_{\Sigma}\left|\dot{I}_{\text {loop }}+\frac{\dot{U}_{S C}}{Z_{\Sigma}}\right|^{2}
$$

\subsection{Relationship between compensation voltage and load node voltage}

Suppose that the UPFC is inserted between node i-1 and i. The UPFC produces the compensation voltage $\dot{U}_{S C}$, as shown in Fig. 2, where $\dot{U}_{1 i}$ is the voltage of load $i$ after compensation and $\dot{I}_{1 i}$ is the current of feeder section $i$.

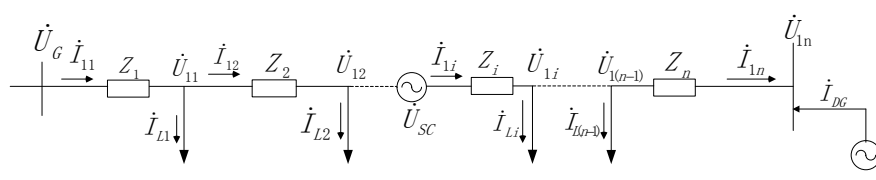

FIGURE 2 Equivalent network after series compensation

Based on the superposition theorem, the network in Fig. 2 can be divided into two parts. The first one is the original network without compensation, as shown in Fig. 1. The other is the network powered only by $\dot{U}_{S C}$, as shown in Fig. 3 . where $\Delta \dot{U}_{i}$ is the voltage difference and $\Delta \dot{I}_{i}$ is the current difference led by $\dot{U}_{S C}$. 


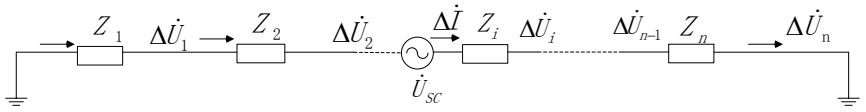

FIGURE 3 Network powered by compensation voltage

The node voltage difference between $Z_{1}$ and $Z_{i-1}$ in Fig. 3 can be expressed as

$$
\Delta \dot{U}_{\mathrm{j}}=-\frac{\dot{U}_{S C} \cdot \sum_{\mathrm{i}=1}^{\mathrm{j}} Z_{i}}{\sum_{i=1}^{\mathrm{n}} Z_{i}} \quad(j=1,2, \cdots, i-1)
$$

The voltage difference of the nodes between $Z_{i}$ and $Z_{n}$ in Fig. 3 can be expressed as

$$
\Delta \dot{U}_{\mathrm{j}}=\frac{\dot{U}_{S C} \cdot \sum_{\mathrm{i}=\mathrm{j}+1}^{n} Z_{i}}{\sum_{i=1}^{\mathrm{n}} Z_{i}} \quad(j=i, i+1, \cdots, n)
$$

The node voltage after compensation in Fig. 2 is

$$
\dot{U}_{1 j}=\dot{U}_{j}+\Delta \dot{U}_{j} \quad(j=1,2, \cdots, n)
$$

The conclusion in 2.1 shows that the power loss is related only to the compensation voltage amplitude, but the node voltage is related to both the amplitude and phase of the compensation voltage. Therefore, the node voltage and power loss can be controlled separately.

\section{Optimal power flow control model for an active distribution network}

Considering the power loss and node voltage deviation, an optimal control model is constructed. The associated multiple-objective optimization problem can be simplified into a single-objective optimal model by designing the membership function.

\subsection{Membership function of power loss}

Suppose that the original power loss before control is $P_{\text {loss-ori }}$ and that the minimal power loss in theory is $P_{l o s s-\min }$. $P_{\text {loss }}^{\prime}$ is the actual power of the network. The membership function of power loss is designed as

$$
\mu_{P_{\text {loss }}=}=\begin{array}{lc}
1 & P_{\text {loss }}^{\prime} \leq P_{\text {loss-min }} \\
\frac{P_{\text {loss }}^{\prime}-P_{\text {loss-ori }}}{P_{\text {loss -min }}-P_{\text {loss-ori }}} & P_{\text {loss-min }}<P_{\text {loss }}^{\prime}<P_{\text {loss-ori }} \\
0 & P_{\text {loss-ori }} \leq P_{\text {loss }}^{\prime}
\end{array}
$$

\subsection{Membership function of load node voltage deviation}

Suppose that voltage varies from $-7 \% U_{N}$ to $+7 \% U_{N}$. The membership function $\mu_{\Delta U i}$ for the voltage of the load node $\mathrm{i}$ is designed as

$$
\mu_{\Delta U i}=\left\{\begin{array}{lc}
0 & U_{i}<0.93 U_{N} \\
\frac{U_{i}-0.93 U_{N}}{0.07 U_{N}} & 0.93 U_{N} \leq U_{i} \leq U_{N} \\
\frac{1.07 U_{N}-U_{i}}{0.07 U_{N}} & U_{N}<U_{i} \leq 1.07 U_{N} \\
0 & U_{i}>1.07 U_{N}
\end{array}\right.
$$

where $U_{N}$ is the rate voltage, $U_{i}$ is the actual voltage of load node $\mathrm{i}$, which is $\dot{U}_{1 j}$ as shown in equation (5), and $\mathrm{n}$ is the total quantity of load node $1 \leq i \leq n$.

\subsection{Optimal control model for power loss and voltage}

The single objective optimal control model is constructed as shown in equation (8). It is based on the membership functions defined in (6) and (7).

$$
\begin{aligned}
& \max \left(\alpha \sum_{i=1}^{n} \frac{\mu_{\Delta U i}}{n}+\beta \mu_{\text {loss }}\right) \\
& \text { s.t }\left\{\begin{array}{l}
S_{G} \leq S_{G \max } \\
U_{\text {min }} \leq U_{i} \leq U_{\text {max }}
\end{array}\right.
\end{aligned}
$$

where $\alpha, \beta$ is the weight coefficient for the power loss and load node voltage $\alpha+\beta=1$, $\mathrm{n}$ is the total quantity of load node $1 \leq i \leq n$, $S_{G}$ is the actual power of the feeder, $S_{G \max }$ is the maximum power capacity of the feeder, $U_{\max }$ and $U_{\min }$ are the upper and lower limits of the load node voltage, respectively, and $U_{i}$ 
is the actual voltage of load node $\mathrm{i}$.

\section{Improved DE algorithm}

To solve the nonlinear optimal control model as shown in (8), an improved DE algorithm is studied.

\subsection{Optimal production of initial population}

Suppose that the population size is NP and $X_{i}$ is the individual vector i. Then, $X_{\mathrm{i}}=\left(x_{i, 1}, x_{i, 2}, \cdots, x_{i, n}\right), X_{i} \in R^{n}$, where $\mathrm{n}$ is the resolution space dimension. In the standard DE algorithm, the individual vector is selected at random but must meet the given bounded constraint. The vector can be expressed as

$$
x_{i, j}=x_{i, j \min }+\operatorname{rand}()\left(x_{i, j \max }-x_{i, j \text { min }}\right)
$$

where $x_{i, j}$ is the component $\mathrm{j}$ of the individual sector $X_{i}$ and $x_{i, j \max }$ and $x_{i, j \min }$ are the upper and lower bounds of $x_{i, j}$, respectively. Rand() signified a random number distributed uniformly from 0 to 1 .

An optimal method for producing the initial generation was previously reported [27]. First, based on (9), one initial generation continues producing randomly until it meets the demand of the given bounded constraint. Then, it is adopted as the first feasible individual and is expressed as $X_{1}^{0}=\left(x_{11}^{0}, x_{12}^{0}, \cdots, x_{1 \mathrm{n}}^{0}\right)$. Second, other individuals are produced randomly based on (9). If they cannot meet the demand of the given bounded constraint, they will be regulated to approach $X_{1}^{0}$ according to (10):

$$
\mathrm{X}_{2}^{0}=X_{1}^{0}+\mu\left(X_{2}^{0}-X_{1}^{0}\right)
$$

where $\mu$ is the contraction coefficient and $\mu \in[0,1)$. If a new individual cannot meet the demand of the given bounded constraint after regulation, $\mu$ will be divided by two automatically until the feasible individual is obtained. In the end, the entire initial population can be obtained successfully. In this paper, the optimal production of the initial population based on (10) is adopted.

\subsection{Improved strategy for the mutation operator}

The adaptive mutation operator is introduced [28], which can broaden the initial population distribution in the feasible region. The adaptive zoom factor $F$ is expressed as

$$
F=F_{0} * 2 e^{(1-G) /\left(G_{\max }+1-G\right)}
$$

where $F_{0}$ is the initial zoom factor, $G_{\max }$ is the maximum evolution generation number, $G$ is the present evolution generation number, and $G \in\left[0, G_{\max }\right]$. During the initial period, the zoom factor $F$ is relatively large to retain population diversity. Subsequently, the zoom factor $\mathrm{F}$ automatically decreases to retain qualified information and provide fast convergence.

There are many variations of the DE algorithm. Among them, the method shown in (12) and (13) performs well and has been used successfully in practical applications [29]:

$$
\begin{gathered}
v_{i}^{t+1}=x_{r 3}^{t}+F^{*}\left(x_{r 1}^{t}-x_{r 2}^{t}\right) \\
v_{i}^{t+1}=x_{\text {gbest }}^{t}+F^{*}\left[\left(x_{r 1}^{t}-x_{r 2}^{t}\right)+\left(x_{r 3}^{t}-x_{r 4}^{t}\right)\right]
\end{gathered}
$$

where ${ }^{v}$ is the new individual, which may be out of the given bounded constraint. $x$ is the basic individual for the mutation operator and can be selected randomly, in which case it is expressed as $x_{r i}^{t}$. It can also be obtained by selecting the optimal individual among the present population, which is expressed as $x_{\text {gbest }}^{t} \mathrm{t}$ is the generation number, and $F$ is the zoom factor. As shown in (12), a new individual is produced by the last three different individuals, which is unrelated to the goal function. It is beneficial to maintain population diversity to enhance the universal searching capability, but this method will influence the DE algorithm 
convergent rate. As shown in (13), the new individual is produced with the guidance of the last optimal individual. It has strong searching capability with a fast convergence rate, but it may not escape from a local optimum, particularly at the initial stage.

A simulated annealing algorithm can change the focus of the mutation operator by the annealing factor $\lambda$, which is expressed as [30]

$$
\lambda=\left(G_{\max }-G\right) / G_{\max }
$$

where $G_{\max }$ is the maximum evolution generation number and $G$ is the present evolution generation number.

Based on (12)-(14), an improved mutation operator algorithm is presented that combines the simulated annealing strategy and adaptive mutation operator. The new mutation operator algorithm can be expressed as

$$
\begin{gathered}
\mathrm{v}_{i}^{G+1}=\lambda x_{r 1}^{G}+(1-\lambda) x_{\text {best }}^{G}+\mathrm{F} \lambda *\left(x_{r 2}^{G}-x_{r 3}^{G}\right)+ \\
F(1-\lambda) *\left(x_{r 2}^{G}-x_{r 3}^{G}+x_{r 4}^{G}-x_{r 5}^{G}\right)
\end{gathered}
$$

where $\lambda \in[0,1]$. When $\lambda=1$, formula (15) is the same as (12), and when $\lambda=0$, formula (15) is the same as (13). During the searching process, $\lambda$ will increase automatically to reduce the weight of (12) and increase the weight of (13). The mutation operator method in (15) can balance the universal searching capability and convergence rate.

Based on the above analysis, the improved DE algorithm is presented based on (10) and (15). It has strong universal searching capability over the initial period and satisfactory local searching capability over subsequent periods. The flow chart of the improved DE algorithm is shown in Fig. 4.

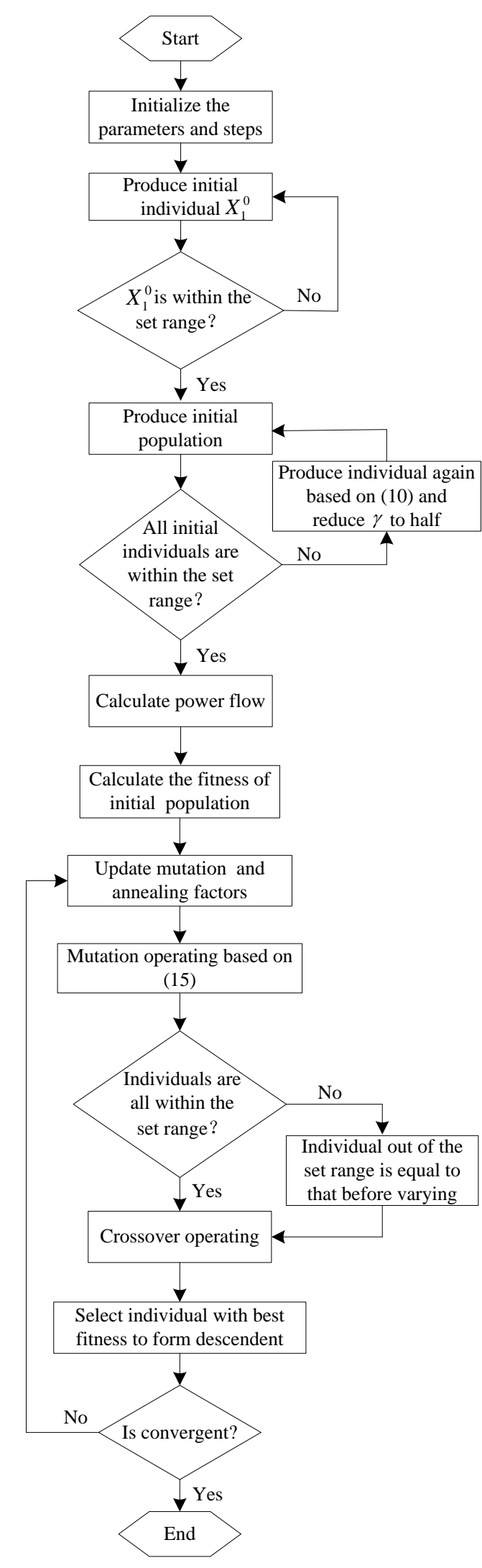

FIGURE 4 Flow chart of improved DE algorithm 


\section{Simulation and analysis}

The simulation model is constructed using PSCAD software. The structure is based on the IEEE 33 standard distribution system as shown in Fig. 5. The load in some nodes is changed, and all the simulating parameters are shown in Tab. 1 . $\mathrm{U}_{\mathrm{N}}=12.66 \mathrm{kV}$. All the branches, including 18-21, 22-24 and 25-32, are simplified into a central load. Then, the main feeder 0-17 is analysed. All loads are described by a constant-current model. DG is connected by node 17 and is simulated as motor type DG, which can be regarded as a voltage source. The improved DE algorithm discussed above is used to solve the optimal control model, where the weight coefficient $\alpha=\beta=0.5$. The size of the population is 20 , and the maximum iteration time is 80. The crossover factor is 0.5 , and the initial mutation factor is 0.6. The improved DE algorithm is implemented by programming in Matlab.

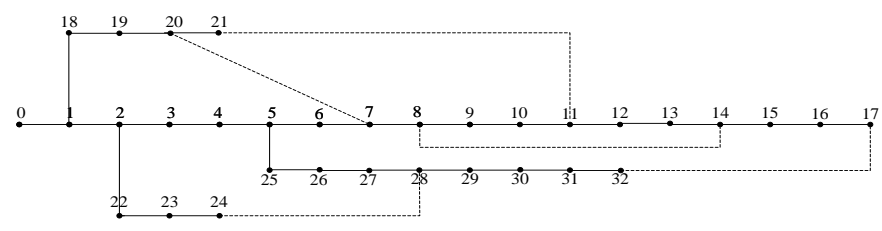

FIGURE 5 IEEE 33 distribution system

TABLE 1 Simulated model parameters

\begin{tabular}{|c|c|c|c|}
\hline Node $\mathrm{i}$ & $\begin{array}{c}\text { Node } \\
\mathrm{j}\end{array}$ & Impedance $(\Omega)$ & $\begin{array}{c}\text { Load j } \\
(\mathrm{kVA})\end{array}$ \\
\hline 0 & 1 & $0.0922+\mathrm{j} 0.047$ & $100+\mathrm{j} 60$ \\
\hline 1 & 2 & $0.4930+\mathrm{j} 0.2511$ & $90+\mathrm{j} 40$ \\
\hline 2 & 3 & $0.3660+\mathrm{j} 0.1864$ & $120+\mathrm{j} 80$ \\
\hline 3 & 4 & $0.3811+\mathrm{j} 0.1941$ & $60+\mathrm{j} 30$ \\
\hline 4 & 5 & $0.8190+\mathrm{j} 0.7070$ & $60+\mathrm{j} 20$ \\
\hline 5 & 6 & $0.1872+\mathrm{j} 0.6188$ & $200+\mathrm{j} 100$ \\
\hline 6 & 7 & $0.7114+\mathrm{j} 0.2351$ & $396+\mathrm{j} 198$ \\
\hline 7 & 8 & $1.0300+\mathrm{j} 0.7400$ & $590+\mathrm{j} 296$ \\
\hline 8 & 9 & $1.0440+\mathrm{j} 0.7400$ & $396+\mathrm{j} 198$ \\
\hline 9 & 10 & $0.1966+\mathrm{j} 0.0650$ & $590+\mathrm{j} 296$ \\
\hline 10 & 11 & $0.3744+\mathrm{j} 0.1238$ & $60+\mathrm{j} 35$ \\
\hline 11 & 12 & $1.4680+\mathrm{j} 1.1550$ & $60+\mathrm{j} 35$ \\
\hline 12 & 13 & $0.5416+\mathrm{j} 0.7129$ & $120+\mathrm{j} 80$ \\
\hline 13 & 14 & $0.5910+\mathrm{j} 0.5260$ & $60+\mathrm{j} 10$ \\
\hline 14 & 15 & $0.7463+\mathrm{j} 0.5450$ & $60+\mathrm{j} 20$ \\
\hline 15 & 16 & $1.2890+\mathrm{j} 1.7211$ & $396+\mathrm{j} 198$ \\
\hline
\end{tabular}

\begin{tabular}{|c|c|c|c|}
\hline 16 & 17 & $0.3720+\mathrm{j} 0.5740$ & 0 \\
\hline 1 & 18 & $0.1640+\mathrm{j} 0.1565$ & $90+\mathrm{j} 40$ \\
\hline 18 & 19 & $1.5042+\mathrm{j} 1.3554$ & $90+j 40$ \\
\hline 19 & 20 & $0.4095+\mathrm{j} 0.4784$ & $90+j 40$ \\
\hline 20 & 21 & $1.7089+\mathrm{j} 0.9373$ & $90+\mathrm{j} 40$ \\
\hline 2 & 22 & $0.4512+\mathrm{j} 0.3083$ & $90+\mathrm{j} 50$ \\
\hline 22 & 23 & $0.8980+\mathrm{j} 0.7091$ & $420+j 200$ \\
\hline 23 & 24 & $0.8960+\mathrm{j} 0.7011$ & $420+j 200$ \\
\hline 5 & 25 & $0.2030+\mathrm{j} 0.1034$ & $60+j 25$ \\
\hline 25 & 26 & $0.2842+\mathrm{j} 0.1447$ & $60+j 25$ \\
\hline 26 & 27 & $1.0590+\mathrm{j} 0.9337$ & $60+\mathrm{j} 20$ \\
\hline 27 & 28 & $0.8042+\mathrm{j} 0.7006$ & $120+\mathrm{j} 70$ \\
\hline 28 & 29 & $0.5075+\mathrm{j} 0.2585$ & $200+j 600$ \\
\hline 29 & 30 & $0.9744+\mathrm{j} 0.9630$ & $150+\mathrm{j} 70$ \\
\hline 30 & 31 & $0.3105+\mathrm{j} 0.3619$ & $210+\mathrm{j} 100$ \\
\hline 31 & 32 & $0.3410+\mathrm{j} 0.5362$ & $60+j 40$ \\
\hline 7 & 20 & $2+\mathrm{j} 2$ & \multirow{5}{*}{$\begin{array}{c}\text { Inter } \\
\text { connection } \\
\text { switch }\end{array}$} \\
\hline 8 & 14 & $2+\mathrm{j} 2$ & \\
\hline 11 & 21 & $2+\mathrm{j} 2$ & \\
\hline 17 & 32 & $0.5+\mathrm{j} 0.5$ & \\
\hline 24 & 28 & $0.5+\mathrm{j} 0.5$ & \\
\hline
\end{tabular}

\subsection{Simulation result of optimal voltage control} 5.1.1 Voltage control effectivity: The simulation results for the load node voltage are shown in Tab. 2, which includes three states to compare the voltage control effect. In State 1, there is no series compensation voltage or DG. In State 2, DG is injected, but there is no series compensation voltage. In State 3, DG is injected and a series compensation voltage is applied, and the optimal control model includes the node voltage and power loss. The compensating apparatus is set at node 8 . Based on equation (8) and the improved DE algorithm in Fig. 4 , the compensating voltage $\dot{U}_{S C}$ can be obtained as $0.512 \angle 81.58^{\circ}$. In State 1, the voltage of node 5-17 is below the lower voltage limit. In State 2, the overall voltage level is improved, but the voltage of node $8-10$ is still below the lower voltage limit. DG can improve the voltage distribution, but it cannot entirely resolve this issue. After performing series compensation as shown in State 3, the voltage of all nodes can meet the constraint of the voltage 
variation range. The simulation results establish the effectiveness of the optimal voltage control strategy. TABLE 2 Comparison of load node voltages

\begin{tabular}{|c|c|c|c|}
\hline $\begin{array}{c}\text { Load } \\
\text { No }\end{array}$ & $\begin{array}{c}\text { Node voltage as } \\
\text { State 1 }\end{array}$ & $\begin{array}{c}\text { Node voltage as } \\
\text { State 2 }\end{array}$ & $\begin{array}{c}\text { Node voltage as } \\
\text { State 3 }\end{array}$ \\
\hline 1 & 0.9957 & 0.9968 & 0.9967 \\
\hline 2 & 0.9746 & 0.9819 & 0.9807 \\
\hline 3 & 0.9623 & 0.9742 & 0.9722 \\
\hline 4 & 0.9499 & 0.9665 & 0.9637 \\
\hline 5 & 0.9191 & 0.9461 & 0.9425 \\
\hline 6 & 0.9101 & 0.9397 & 0.9373 \\
\hline 7 & 0.8959 & 0.9344 & 0.9300 \\
\hline 8 & 0.8755 & 0.9269 & 0.9338 \\
\hline 9 & 0.8601 & 0.9248 & 0.9300 \\
\hline 10 & 0.8582 & 0.9253 & 0.9300 \\
\hline 11 & 0.8560 & 0.9279 & 0.9315 \\
\hline 12 & 0.8473 & 0.9379 & 0.9395 \\
\hline 13 & 0.8438 & 0.9417 & 0.9434 \\
\hline 14 & 0.8412 & 0.9468 & 0.9478 \\
\hline 15 & 0.8383 & 0.9536 & 0.9534 \\
\hline 16 & 0.8330 & 0.9662 & 0.9660 \\
\hline 17 & 0.8330 & 0.9716 & 0.9716 \\
\hline
\end{tabular}

5.1.2 Power loss control effectivity: Simulation results for power loss in different conditions are shown in Fig. 6, in which State 1, State 2 and State 3 are the same as defined in 5.1.1. In State 4, DG is injected and a series compensation voltage is applied, but the optimal control model consists only of power loss. The power loss in State 1 is 0.4942 MW. In State 2, it is 0.2724 MW. Therefore, the injected DG can decrease the power loss. The power loss of the active distribution network in State 4 is the minimum in theory, and it is 0.2149 MW. In State 3, it is 0.2378 MW. The power loss in State 3 is larger than that in State 4 because the series compensating control strategy in State 3 includes simultaneous voltage and power loss. In State 4 , the power loss is minimized. The difference between State 3 and State 4 is the weight coefficients $\alpha$ and $\beta$, which are set according to the actual demand [20]. A comparison of State 2 and State 3 confirms that the optimal voltage control method can decrease the power loss.

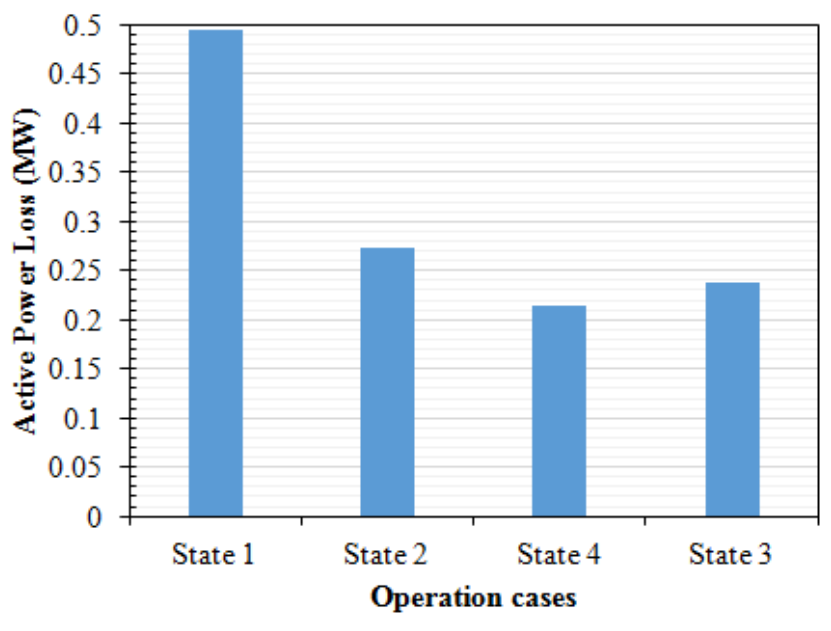

FIGURE 6 Power loss at different conditions

\subsection{Simulation for improved $D E$ algorithm}

5.2.1 Speed of producing the initial population:

The speed of producing the initial population can affect the time to solve the optimization object. The results for different DE algorithms are shown in Tab. 3. The improved DE algorithm is faster than the standard DE algorithm when the population scale is known. Increasing the population requires more time to produce the initial population, but the improved DE algorithm offers absolute advantages in producing the initial population.

TABLE 3 Time contrast for producing different scale populations with varying DE algorithm

\begin{tabular}{|c|c|c|}
\hline $\begin{array}{c}\text { Scale } \\
\text { population }\end{array}$ & $\begin{array}{c}\text { Time with } \\
\text { standard DE (s) }\end{array}$ & $\begin{array}{c}\text { Time with } \\
\text { improved DE } \\
(\mathrm{s})\end{array}$ \\
\hline 10 & 0.087263 & 0.013623 \\
\hline 20 & 0.204181 & 0.018638 \\
\hline 30 & 0.270601 & 0.021246 \\
\hline 40 & 0.339764 & 0.023020 \\
\hline 50 & 0.408676 & 0.025390 \\
\hline 60 & 0.556561 & 0.032148 \\
\hline
\end{tabular}

5.2.2 Convergence speed contrast: Suppose that the population scale is 20 , the maximum iteration time is 80 , the crossover factor is 0.5 , the initial mutation factor $\mathrm{F} 0$ is 0.6 , the normal mutation factor $F$ is 1 , and $\alpha=\beta=0.5$. The simulated satisfaction value of different DE algorithms is shown in Fig. 7. The results of the standard DE, adaptive DE [30][31] and improved DE algorithm are compared. The improved DE algorithm has a 
clear advantage in the convergence rate based on universal optimization. Because the beginning mutation factor is improved and the variation probability is much larger, the improved algorithm is slower than the standard DE in the initial period, but the mutation factor is adjusted to decrease with the calculation process, and the global optimal solution can be obtained with fewer steps by the improved DE algorithm.

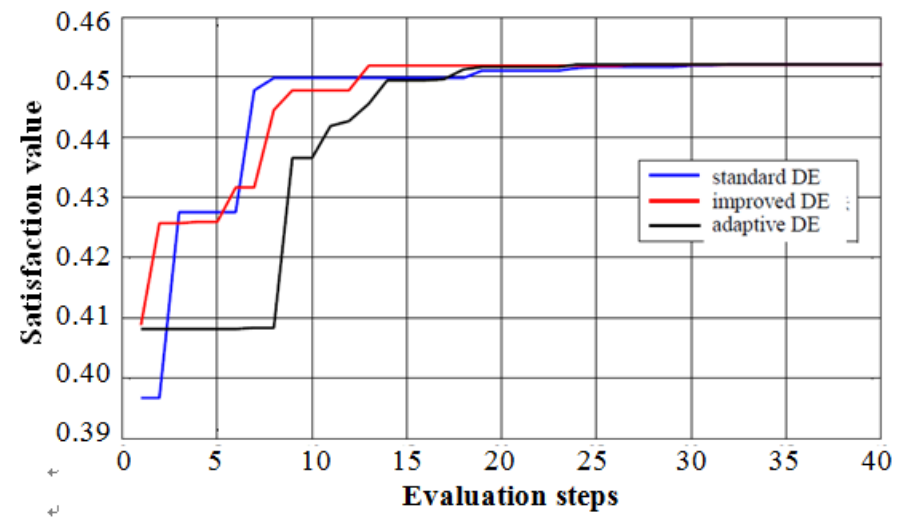

FIGURE 7 Satisfaction value curve with three DE algorithms

To confirm the reliability of the DE algorithm, 100 testing experiments were conducted to solve the same optimal object with the three different DE algorithms. The static probability of convergence steps with the different algorithms is shown in Fig. 8. In most cases, the standard DE algorithm requires approximately 30 to 40 steps, and the improved DE and adaptive DE algorithm can complete optimization in 20 to 30 steps. The probability of the improved DE in this zone is greater than that of the adaptive DE algorithm.

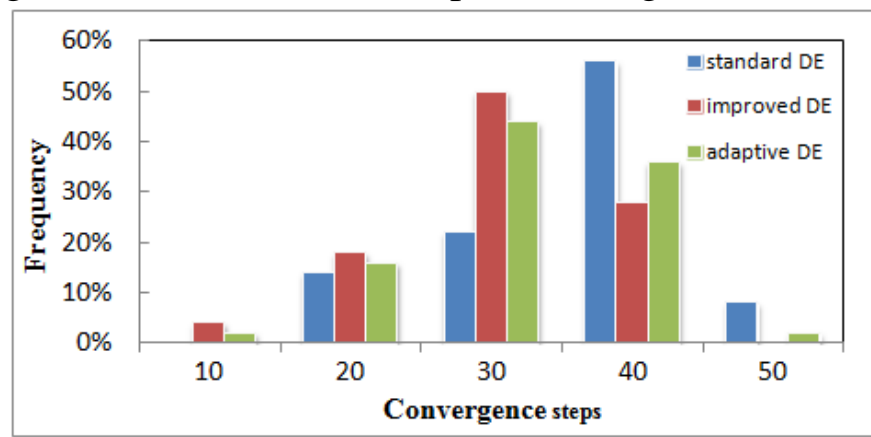

FIGURE 8 Static convergence step distribution for three DE algorithms

\section{Conclusions}

When DG is connected into a distribution network, the voltage tends to become degraded. To resolve the voltage issue in an active distribution network, the optimal voltage control method, which analyses the power loss in terms of series compensating theory, is studied. An optimal control model is developed that incorporates the power loss and node voltage. An improved DE algorithm is introduced to effectively solve the optimal voltage control model. Simulations based on the IEEE 33 distribution network confirm that the voltage control method can decrease the power loss and improve the load node voltage. The improved DE algorithm can solve the optimal model universally with higher efficiency and convergence speed than the standard DE and adaptive DE algorithms. The method presented is also suitable for optimal power flow control in normally looped distribution systems with dual sources.

With the development of modern power electronics technology and advanced control theory, active control measures based on FACTS are expected to be applied widely in future distribution networks. Increasingly more DG will be injected into distribution networks. The optimal voltage control method presented in this paper provides a theoretical foundation for the further development of active distribution networks.

\section{Acknowledgements}

This work was supported by the National Natural Science Foundation of China (No. 51177096) and the Fundamental Research Funds for the Central Universities (No. 13CX02101A).

\section{References}

1. Bollen M.H.J. Understanding power quality problems, voltage sags and interruptions [M]. IEEE PRESS, 2000.

2. Bernardo H. T. Seelig, Lindomar J. de Souza and Ricardo B. Prada. Voltage control in heavily loaded networks. International Transactions on Electrical Energy Systems. 2015,25(12): 3275-3287. 
3. R. A. Walling, R. Saint, R. C. Dugan, J. Burke and L. A. Kojovic, Summary of distributed resources impact on power delivery systems [J], IEEE Transactions on Power Delivery, 2008,23(3): 1636-1644.

4. Sultan S. Al Kaabi, H. H. Zeineldin, Vinod Khadkikar, Planning Active Distribution Networks Considering Multi-DG Configurations [J]. IEEE Transactions on Power System. 2014,29(2) :785 -793.

5. Fernando Bastião, Paulo Cruz, Rui Fiteiro. Impact of Distributed Generation on Distribution Networks[C]. International Conference on Electricity Market, 2008:16.

6. McDermott T.E., Dugan R.C . PQ, reliability and $\mathrm{DG}[\mathrm{J}]$. IEEE Magazine on Industry Application,2003,9(5):17-23.

7. Slootweg J G, Kling W L. Impacts of distributed generation on power system transient stability[C]. 2002 IEEE Power Engineering Society Summer Meeting, Chicago, United States, 2002:862-867.

8. Kai Zou, Ashish P. Agalgaonkar, Kashem M. Muttaqi, Sarath Perera, An Analytical Approach for Reliability Evaluation of Distribution Systems Containing Dispatchable and Nondispatchable Renewable DG Units [J]. IEEE Trans. Smart Grid. 2014, 5(6):2657- 2665.

9. Vito Calderaro, Gaspare Conio, Vincenzo Galdi, Giovanni Massa, etc, Optimal Decentralized Voltage Control for Distribution Systems With InverterBased Distributed Generators [J]. IEEE Transactions on Power Systems. 2014, 29(1):230-241.

10. Pitchaimuthu Raja, Manickavasagam Parvathy Selvan, Natarajan Kumaresan, Enhancement of voltage stability margin in radial distribution system with squirrel cage induction generator based distributed generators [J]. IET Generation, Transmission \& Distribution. 2013,7(8):898906.

11. Elkhatib M.E, El Shatshat R, Salama M.M.A. Optimal control of voltage regulators for multiple feeders $[\mathrm{J}]$. IEEE Transactions on Power Delivery, 2010, 25(4):2670-2675.

12. Viawan F, Karlsson D. Combined Local and Remote Voltage and Reactive Power Control in the Presence of Induction Machine Distributed Generation[J]. IEEE Transactions on Power Systems, 2007, 22(4):2003-2012.

13. Farag H.E.Z, El-Saadany E.F. A Novel Cooperative Protocol for Distributed Voltage Control in Active Distribution Systems[J]. Power Systems IEEE Transactions on, 2013, 28(2):1645-1656.
14. Miranda V, Moreira A, Pereira J. An Improved Fuzzy Inference System for Voltage/VAR Control [J]. IEEE Transactions on Power Systems, 2007,22(4):2013-2020.

15. Mao Yiming, Miu K.N. Switch Placement to Improve System Reliability for Radial Distribution Systems with Distributed Generation[J]. IEEE Transactions on Power Systems, 2003, 18(10):1346-1352.

16. S.A. Miske . Considerations for the Application of Series Capacitors to Radial Power Distribution Circuits $[\mathrm{J}]$. IEEE Transactions on Power Delivery,2001,16(2).

17. Faried S.O, Aboreshaid S. Stochastic Evaluation of Voltage Sags in Series Capacitor Compensated Radial Distribution Systems[J] .IEEE Power Engineering Review,2002,22(11):63-63.

18. Majid Moradlou and Hamid Reza Karshenas. Compensation range calculation in an interline dynamic voltage restorer (IDVR) encountering different voltage sag types. International Transactions on Electrical Energy Systems. 2014,24(7):992-1005 .

19. Senjyu T, Yunaha Y, Yona A. Stable Operation for Distribution Generators on Distribution System Using UPFC[C]. Transmission \& Distribution Conference \&Exposition Asia and Pacific, $2009: 1-4$.

20. ZHANG Zhi-hua, XU Bing-yin, CHEN Qing, An Overall Cost Based on Optimal Power Flow Control Method of Dual-source Distribution Network with Closed Loop Operation Using UPFC.IEEJ Transactions on Electrical and Electronic Engineering. 2016,11(6): 708-713

21. SAYED M A, TAKESHITA T. All nodes voltage regulation and line loss minimization in loop distribution systems using UPFC[C].Energy Conversion Congress and Exposition.2009.

22. JY Liu, YH Song and PA Mehta. Strategies for handling UPFC constraints in steady-state power flow and voltage control. IEEE Transactions on Power Systems. 2000, 15(2):566-571.

23. Yan YANG. Optimal power flow based on differential evolution[D]. Southwest Jiaotong University,2009.

24. STORN R, PRICE K. Differential Evolution a simple and efficient adaptive scheme for global optimization over continuous spaces[C]. Technical Report TR95-012, International Computer Science Institute, Berkley, 1995.

25. STORN R. System design by constraint adaptation and differential evolution[J]. IEEE Trans on Evolutionary Computation, 1999, 3(1):22-34.

26. H.R. Cai, C.Y.Chung, K.P.Wong. Application of Differential Evolution Algorithm for Transient Stability 
Constrained Optimal Power Flow[J]. IEEE Transactions on Power Systems, 2008, 23(02):719-728.

27. Fulin WANG, Changyou WU, Hui YANG. Study on the productive method on the initial population by using genetic algorithms to solve the constrained optimization problems[J]. Journal of Northeast Agricultural University, 2004, 35(05):608-611.

28. Xuefeng YAN,Juan YU, Feng QIAN. Adaptive mutation differential evolution algorithm and its application to estimate soft sensor parameters[J]. Control Theory \& Applications, 2006,23(05):744-748.

29. YANG Yan, DAI Chao-hua.Optimal power flow based on differential evolution. Journal of Southwest University for Nationalities. Natural Science Edition. 2009,35(5):1057-1062

30. Yan LI, Dongfeng WANG, Songming JIAO, Pu HAN. Thermal Process Identification Using Differential Evolution Algorithm and Radial Basis Function Neural Network[J].Proceedings of the CSEE, 2010,30(08):110116.

31. J. Brest, S. Greiner, B. Boskovic, M. Mernik, V. Zumer. Self-adapting control parameters in differential evolution: A comparative study on numerical benchmark problems [J]. IEEE Trans. Evol. Computat, 2006, 10(06):646-657.

32. Arnel Glotic, Adnan Glotic, Peter Kitak, Joze Pihler, Igor Ticar. Parallel Self-Adaptive Differential Evolution Algorithm for Solving Short-Term Hydro Scheduling Problem[J]. IEEE Transactions on Power Systems, 2014, 29(05):2347-2358. 